Article

\title{
Thermodynamic Performance and Optimization Analysis of a Modified Organic Flash Cycle for the Recovery of Low-Grade Heat
}

\author{
Kyoung Hoon Kim \\ Department of Mechanical Engineering, Kumoh National Institute of Technology, Gyeongbuk 39177, Korea; \\ khkim@kumoh.ac.kr; Tel.: +82-54-478-7292
}

Received: 1 January 2019; Accepted: 28 January 2019; Published: 30 January 2019

\begin{abstract}
The recently proposed organic flash cycle (OFC) has the potential for the efficient recovery of low-grade heat, mainly due to the reduction of irreversibilities in the heat input unit. In the present study, a modified OFC (OFCM) employing a two-phase expander (TPE) and regeneration is proposed and thermodynamic and optimization analysis on this cycle is conducted compared with the basic OFC (OFCB). Six substances are considered as the working fluids. Influences of flash temperature, source temperature, and working fluid are systemically investigated on the system performance. Results showed that OFCM is superior to OFCB in the aspects of power production, thermal, and second-law efficiencies.
\end{abstract}

Keywords: organic flash cycle; regeneration; two-phase expander; low-grade heat source; efficiency; optimization

\section{Introduction}

The organic Rankine cycle (ORC) and Kalina cycle (KC) have attracted much attention as they have been recognized as the most competitive methods for the conversion of a low-grade heat source [1]. ORC, which uses refrigerants or organic substances as working fluid, has many advantages and is considered as a promising solution [2,3]. The ORC with a regenerative heat exchanger can reduce the heat input to the system and improve the thermal efficiency by preheating the working fluid entering the evaporator [4], and the cascaded ORC can achieve an improved performance [5]. Combined cycles based on ORC also can utilize the energy source more efficiently. Various cycles, such as the combined cycle of an ORC and refrigeration [6]; combined cycle of ORC and liquefied natural gas (LNG) cold energy [7]; combined cooling, heating, and power generation cycle [8]; and solar ORC [9] have been proposed and investigated. Bao and Zhao [10], Recompte et al. [11], Pethrrajan et al. [12], Mahmoudi et al. [13], Shi et al. [14], and Garcia et al. [15] have reviewed the studies, both theoretical and experimental, on ORC.

When the ORC is activated by a finite thermal source, the source fluid temperature varies linearly, while the working fluid temperature remains at a constant temperature during the evaporation process. Therefore, a great temperature difference between the fluids in the evaporator is inevitable, which causes a big irreversibility and exergy destruction. For the power generation systems to recover the finite thermal sources, using zeotropic mixture as a working fluid instead of pure substance can remedy the temperature mismatching and reduce the exergy destruction in the evaporator, owing to the changing temperature of working fluid at constant pressure [16,17].

The power flash cycle is a generalized trilateral cycle where the pressurized liquid is heated up to a saturated liquid and then expanded to produce power [18]. The OFC that was proposed in 2012 by Ho et al. [19] is a power generation cycle in which the working fluid remains in a liquid state in the 
evaporator and then flash evaporated. They proposed four modified OFCs with a single flash-double expander, double flash-double expander, single flash-single expander-TPE, and double flash-double expander-TPE [20]. In an OFC, the exergy destruction in the evaporator is drastically reduced owing to the decreased mismatching of temperatures, where an additional exergy destruction due to flash process is required instead [21].

Lee et al. [22] presented a thermodynamic performance comparison of OFC and ORC, and Mondal and De [23] compared OFC with other power generation cycles. A power cycle or combined power and refrigeration cycle based on OFC employing an ejector instead of a throttle valve were also investigated [24,25]. Li et al [26] performed a comparison study on OFC, ORC, and a trilateral Rankine cycle. Nemati et al. [27] investigated effects of flash temperature on the exergoeconomic performance of OFCB and OFCMs with a single flash-double expander, double flash-double expander, single flash-single expander-TPE, and single flash-double expander-TPE in terms of exergy and economics. Baccioli and Antonelli [28] carried out an off-design analysis of OFCB and OFCM with single flash-single expander-regeneration, and Baccioli et al. [29] performed a technical and economic analysis of OFCMs with a double flash-double expander and double flash-double expander-regeneration. Mossaffa and Zareei [30] reported a thermoeconomic analysis of geothermal power plants based on different types of OFCMs with and without regeneration by using an internal heat exchanger (IHE). Kim et al. [31] revealed that the Kalina flash cycle has better power production and thermal efficiency than a KC.

OFC has great potential for the use of low-grade heat sources, but there are still very few reports of related research as compared to ORC. The main purpose of the present work is to propose an OFCM employing regeneration and TPE, and to comparatively investigate the thermodynamic performance of OFCB and OFCM. Six working fluids of isobutane (R600a), butane (R600), R245fa, R123, isopentane (R601a), and o-xylene were considered. Influence of the working fluid, flash and source temperatures, and cycle configuration on the system performance, such as mass flow rates, heat transfers, powers, pressure ratio, and specific volume flow rate, as well as the net power production and efficiency were parametrically investigated. The optimum performances for the maximum second-law efficiency were also studied with respect to the source temperature, and the most suitable working fluids were proposed. In OFCs, the working fluid is heated in the heater till it becomes a saturated liquid, so it remains liquid throughout the heater. When the working fluid temperature at the heater exit is near its critical temperature, the effects of a nonlinear temperature profile of the working fluid are important on the performance of the system, especially on the position of the pinch point difference. The present paper showed the temperature profiles of the streams in the heater and condenser for various flash and also the source temperatures under optimum conditions. The summary of the previous works and this work are listed in Table 1, where $T_{S}$ is the source temperature and $m_{S}$ is the mass flow rate of source.

Table 1. Summary of articles for OFCs.

\begin{tabular}{|c|c|c|c|c|c|c|}
\hline Reference & $\begin{array}{c}\text { Ho } \\
\text { et al. [20] }\end{array}$ & $\begin{array}{l}\text { Nemati } \\
\text { et al. [27] }\end{array}$ & $\begin{array}{c}\text { Baccioli et } \\
\text { al. [28] }\end{array}$ & $\begin{array}{l}\text { Baccioli } \\
\text { et al. [29] }\end{array}$ & $\begin{array}{l}\text { Mosaffa } \\
\text { et al. [30] }\end{array}$ & $\begin{array}{c}\text { Present } \\
\text { Work }\end{array}$ \\
\hline year & 2012 & 2018 & 2018 & 2017 & 2018 & 2019 \\
\hline flash & SDSSS & SDSSS & SS & DD & SDSD & SS \\
\hline expander & SDDSD & SDDSD & SS & DD & SDSD & SS \\
\hline TPE & NNNYY & NNNYY & $\mathrm{NN}$ & NN & NNNN & NY \\
\hline regeneration & NNNNN & NNNNN & NY & NY & NNYY & NY \\
\hline$T_{S}\left({ }^{\circ} \mathrm{C}\right)$ & 300 & $290-310$ & $150-210$ & $80-170$ & 170 & $140-300$ \\
\hline$m_{S}(\mathrm{~kg} / \mathrm{s})$ & - & 17 & - & - & 10 & 1 \\
\hline no. of fluids & 10 & 5 & 16 & 8 & 1 & 6 \\
\hline opt. fluid & - & - & R601a & R601a & R123 & R601a \\
\hline remarks & first proposal & exergo-economic & - & off-design & regeneration by IHE & - \\
\hline
\end{tabular}




\section{System Analysis}

As shown in Figure 1, an OFCB is composed of a source heater, flash evaporator, turbine, expansion valve, condenser, and pump, while an OFCM is equipped with a TPE instead of the throttle valve in the flash evaporator and with regeneration. The cycle description of an OFCM is as follows [22]:

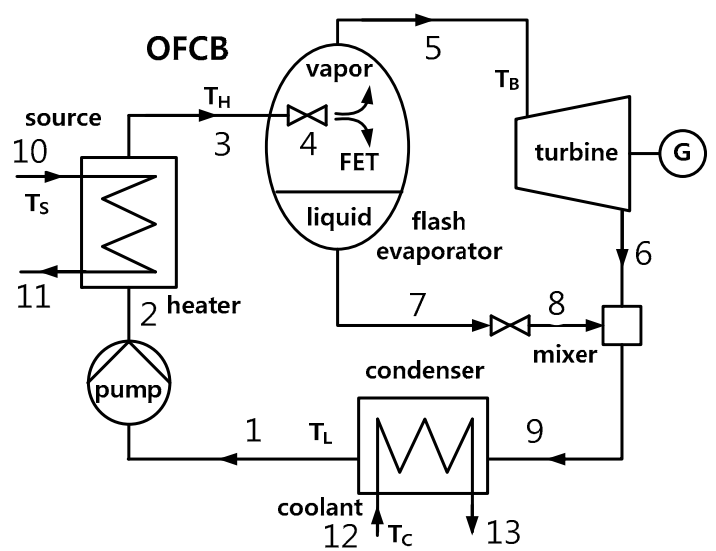

(a)

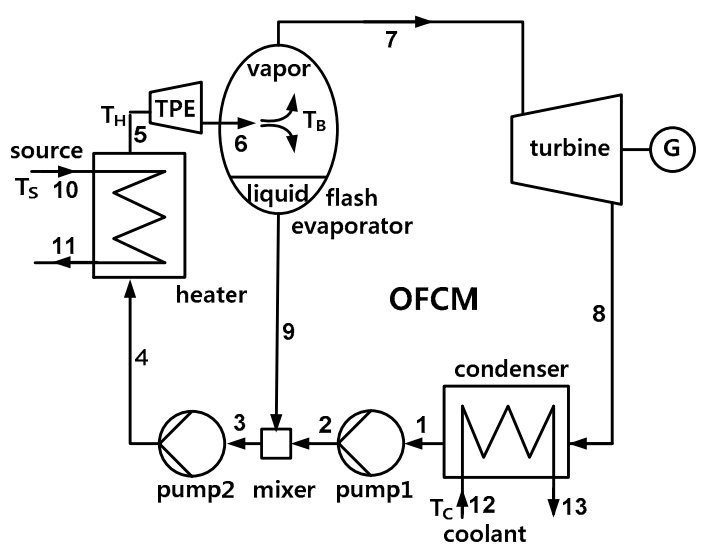

(b)

Figure 1. Systems under consideration: (a) OFCB and (b) OFCM.

Let the working fluid temperatures at the heater exit, flash evaporator, and condenser exit be $T_{H}$, $T_{F}$, and $T_{L}$, respectively. Then, the corresponding saturated pressures $P_{H}, P_{F}$, and $P_{L}$ become the high, middle, and low pressures of the system, respectively. A source fluid at temperature $T_{S}$ (state 10) is supplied to the heater and leaves after heating the working fluid (state 11). The coolant enters the condenser at temperature $T_{C}$ (state 12) and leaves (state 13), meanwhile the working fluid exits the condenser as saturated liquid at $T_{L}$ (state 1). The fluid is pressurized with pump 1 to the flash pressure $P_{F}$ (state 2) and mixed (state 3) with the liquid from the flash evaporator (state 9). Then the fluid is pressurized again with pump 2 to the heater pressure $P_{H}$ (state 4), and is heated up till it becomes the saturated liquid (state 5). The fluid is then expanded in TPE to the flash pressure $P_{F}$ (state 6) and separated into a saturated vapor (state 7) and a saturated liquid (state 9) in the flash evaporator. The vapor from the flash evaporator is expanded in the turbine to the pressure $P_{L}$ after producing power and enters the condenser (state 8). The regeneration is achieved by preheating the working fluid from the pump 1 with the liquid from the flash evaporator.

To simplify the system analysis, following hypotheses are adopted [22,27]:

(1) Pressure losses are neglected in heat exchangers and pipelines.

(2) Heat losses are ignored in components.

(3) Each of the pumps, turbine, and expander has a constant isentropic efficiency.

(4) The working fluids leaving the heater, bottom of flash evaporator, and condenser are saturated liquids at temperatures $T_{H}, T_{F}$, and $T_{L}$, respectively.

(5) The working fluid that exits the mixer and enters pump 2 is liquid.

(6) The pinch temperature difference is given as $\Delta T_{p p}$.

The source fluid temperature at the heater exit, $T_{11}$ is determined from the condition of the pinch temperature difference, and the mass flow rates $m_{5}, m_{7}$, and $m_{9}$ can be evaluated from the mass and energy balances using:

$$
\begin{gathered}
m_{5}=\frac{m_{s} c_{p s}\left(T_{10}-T_{11}\right)}{h_{5}-h_{4}} \\
m_{7}=\frac{m_{5}\left(h_{6}-h_{9}\right)}{h_{7}-h_{9}}
\end{gathered}
$$




$$
m_{9}=m_{5}-m_{7}
$$

where $m$ is the mass flow rate, $T$ the temperature, $h$ the specific enthalpy, $c_{p}$ the isobaric specific heat, and the subscript $s$ denotes the source.

Then, the heat input at heater $Q_{s}$, heat rejection at condenser $Q_{c}$, TPE power WTPE, turbine power $W_{t}$, pump power $W_{p}$, net system power $W_{\text {net }}$, and thermal efficiency $\eta_{t h}$ can be evaluated as

$$
\begin{gathered}
Q_{s}=m_{5}\left(h_{5}-h_{4}\right) \\
W_{t}=m_{7}\left(h_{7}-h_{8}\right) \\
W_{T P E}=m_{5}\left(h_{5}-h_{6}\right) \\
W_{p}=m_{7}\left(h_{2}-h_{1}\right)+m_{5}\left(h_{4}-h_{3}\right) \\
W_{\text {net }}=W_{t}+W_{T P E}-W_{p} \\
\eta_{t h}=\frac{W_{\text {net }}}{Q_{s}}
\end{gathered}
$$

The exergy of the fluid can be evaluated as:

$$
E=m\left[h-h_{0}-T_{0}\left(s-s_{0}\right)\right]
$$

where $s$ is specific entropy and subscript 0 represents dead state. The cycle second-law efficiency, $\eta_{I I}$, is defined as the ratio of the net system power to the exergy input to the system. [22]:

$$
\eta_{I I}=W_{\text {net }} /\left(E_{10}-E_{11}\right)
$$

In this work six substances of butane, isobutene, R245fa, R123, isopentane, and o-xylene working fluids are considered and the thermodynamic properties of the working fluids are evaluated by using the Patel-Teja equation of state $[32,33]$ with MathCAD programming. The code for calculating thermodynamic properties of this work is same as that of Reference [22], and it was reported that the simulation results of Reference [22] for OFCB by using this code were in good agreement with those of Reference [27] using engineering equation solver (EES). The basic thermodynamic data for the working fluids are listed in Table 2 [34].

Table 2. Basic data for working fluids [34].

\begin{tabular}{ccccc}
\hline Substance & $\boldsymbol{M}(\mathbf{k g} / \mathbf{k m o l})$ & $\boldsymbol{T}_{\boldsymbol{c r}}\left({ }^{\circ} \mathbf{C}\right)$ & $\left.\boldsymbol{P}_{\boldsymbol{c r}} \mathbf{( M P a}\right)$ & $\boldsymbol{\omega}$ \\
\hline isobutane & 58.123 & 134.99 & 3.648 & 0.177 \\
butane & 58.123 & 152.03 & 3.797 & 0.199 \\
R245fa & 134.048 & 154.05 & 3.640 & 0.3724 \\
R123 & 136.467 & 183.75 & 3.674 & 0.282 \\
isopentane & 72.150 & 187.28 & 3.381 & 0.228 \\
o-xylene & 106.167 & 357.22 & 3.734 & 0.313 \\
\hline
\end{tabular}

\section{Results and Discussion}

The source was considered to be air with $T_{s}=150^{\circ} \mathrm{C}$ and $m_{S}=1 \mathrm{~kg} / \mathrm{s}$, and the basic conditions for the simulation are listed in Table 3. 
Table 3. Basic conditions for analysis.

\begin{tabular}{cccc}
\hline Symbol & Parameter & Data & Unit \\
\hline$T_{S}$ & source temperature & 150 & ${ }^{\circ} \mathrm{C}$ \\
$T_{H}$ & heating temperature & 135 & ${ }^{\circ} \mathrm{C}$ \\
$T_{F}$ & flash temperature & 80 & ${ }^{\circ} \mathrm{C}$ \\
$T_{L}$ & condensation temperature & 40 & ${ }^{\circ} \mathrm{C}$ \\
$T_{C}$ & cooling water temperature & 25 & ${ }^{\circ} \mathrm{C}$ \\
$T_{0}$ & reference dead state temperature & 25 & ${ }^{\circ} \mathrm{C}$ \\
$\Delta T_{p p}$ & pinch temperature difference & 8 & ${ }^{\circ} \mathrm{C}$ \\
$\eta_{p}$ & isentropic efficiency of pump & 80 & $\%$ \\
$\eta_{t}$ & isentropic efficiency of turbine & 80 & $\%$ \\
$\eta_{T P E}$ & isentropic efficiency of TPE & 65 & $\%$ \\
\hline
\end{tabular}

\subsection{Effects of Flash Temperature}

The effects of varying flash temperature on the thermodynamic performance of OFCB and OFCM are comparatively discussed in this section. In the analysis the heating temperature $T_{H}$, the temperature of working fluid leaving the heater in the OFCB and OFCM, is taken to be as follows to avoid the instability near the critical point as follows [22]:

$$
T_{H}=\min \left(T_{s}-15, T_{c r}-10\right)
$$

Figures 2 and 3 show the temperature profiles of the fluids in heater and condenser in the OFCB and OFCM, respectively, using R123 for different flash temperatures. Here, $H$ denotes the dimensionless heat transfer in a heat exchanger defined as follows:

$$
H=\frac{h-h_{L}}{h_{R}-h_{L}}
$$

where $h_{L}$ and $h_{R}$ indicate the enthalpies at the left and right end of the heat exchanger, respectively. In the $\mathrm{OFCB}$, the temperature distributions of streams in the heater and condenser were slightly influenced by the variation of the flash temperature, and the working fluid entered the condenser as a subcooled liquid irrespective of the flash temperature. In the OFCM, however, the temperature distributions were greatly affected by the varying flash temperature. The higher flash temperature resulted in a higher temperature of the working fluid entering the heater, a higher temperature of the source fluid leaving the heater, and a higher temperature of the working fluid entering the condenser.

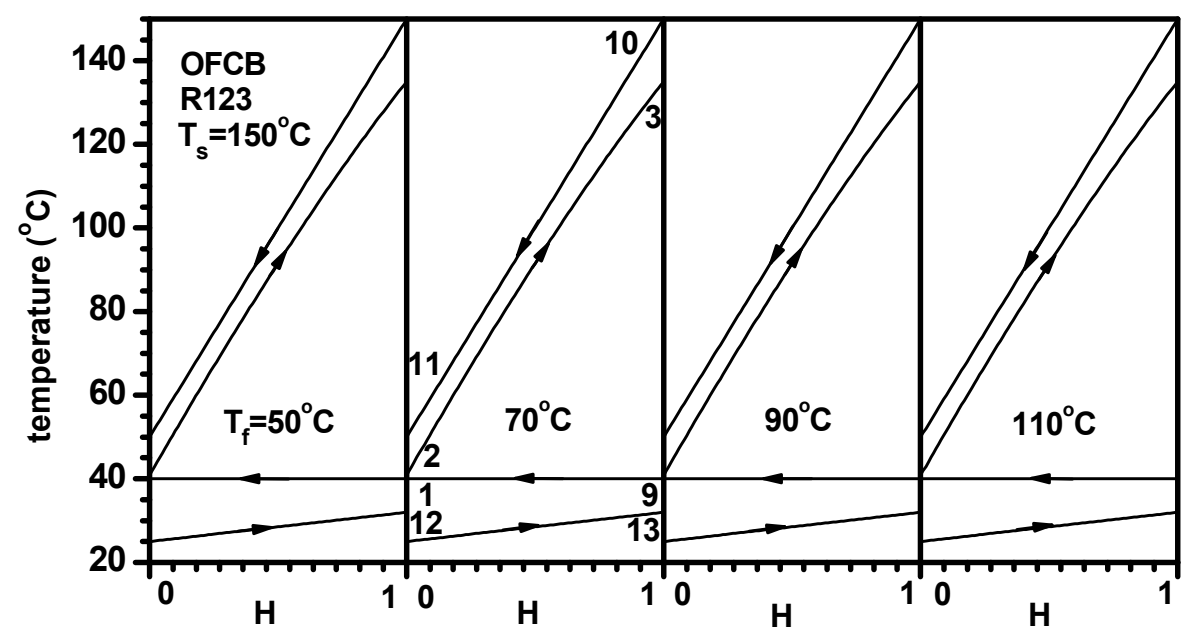

Figure 2. Temperature distributions in the heater and condenser in the OFCB. 


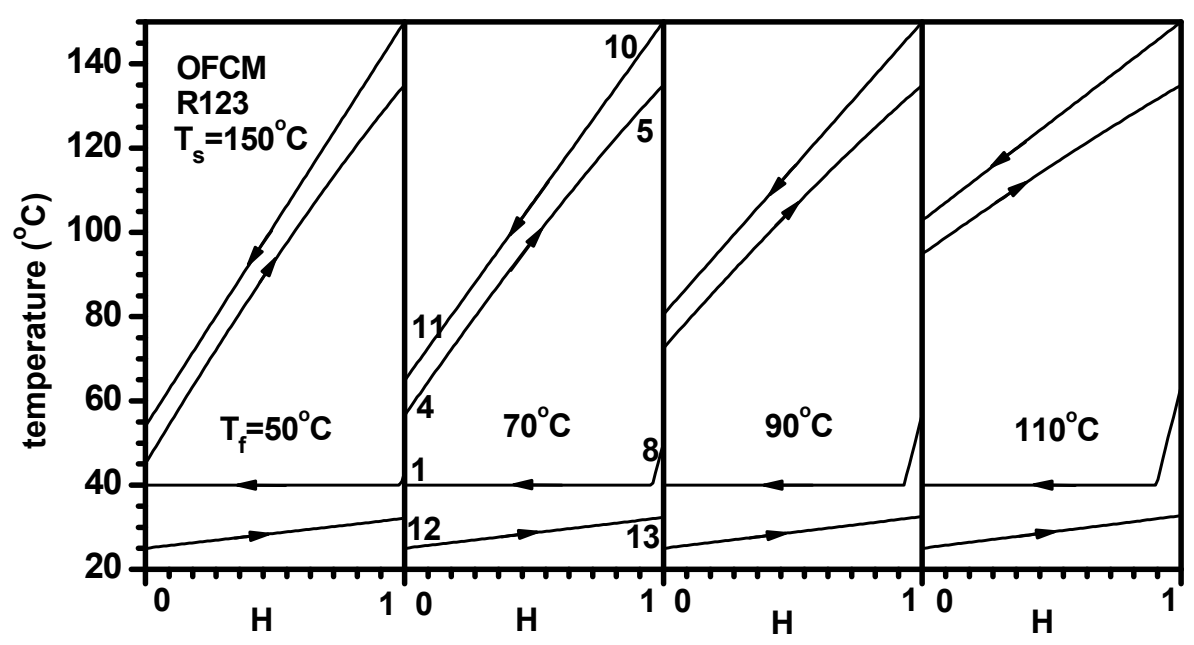

Figure 3. Temperature distributions in the heater and condenser in the OFCM.

Figure 4 shows the influence of the flash temperature on the mass flow rates at heater and turbine. In the figures, $\mathrm{B}$ and $\mathrm{M}$ indicate the OFCB and OFCM, respectively. In OFCB, the mass flow rate at the heater was kept almost constant even as the flash temperature changed for all of the working fluids, since the change of fluid temperature across the pump was negligible. In the OFCM, the mass flow rate also remained almost constant, even as the flash temperature increased, as long as the flash temperature was not high. However, when the flash temperature was high, the mass flow rate increased abruptly with the flash temperature. This can be explained as follows. For specified values for $T_{S}, T_{H}$, and $T_{L}$, as flash temperature increases, the quality in the flash evaporator decreases, so the mass flow rate of liquid leaving the flash evaporator increases and the regeneration effect increases.

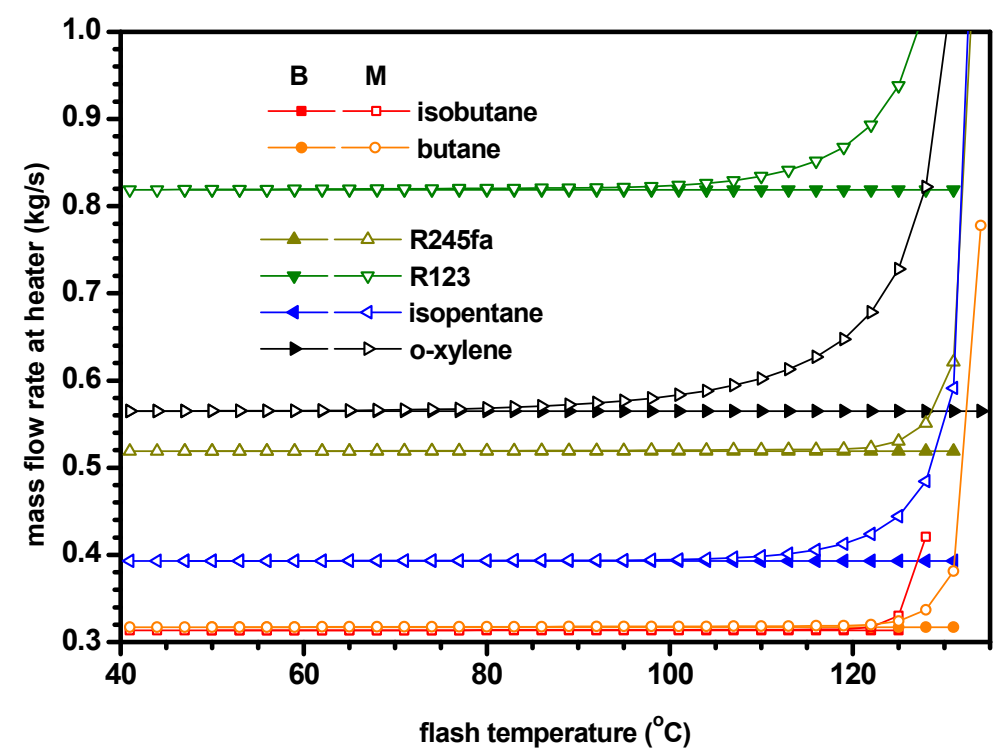

(a)

Figure 4. Cont. 


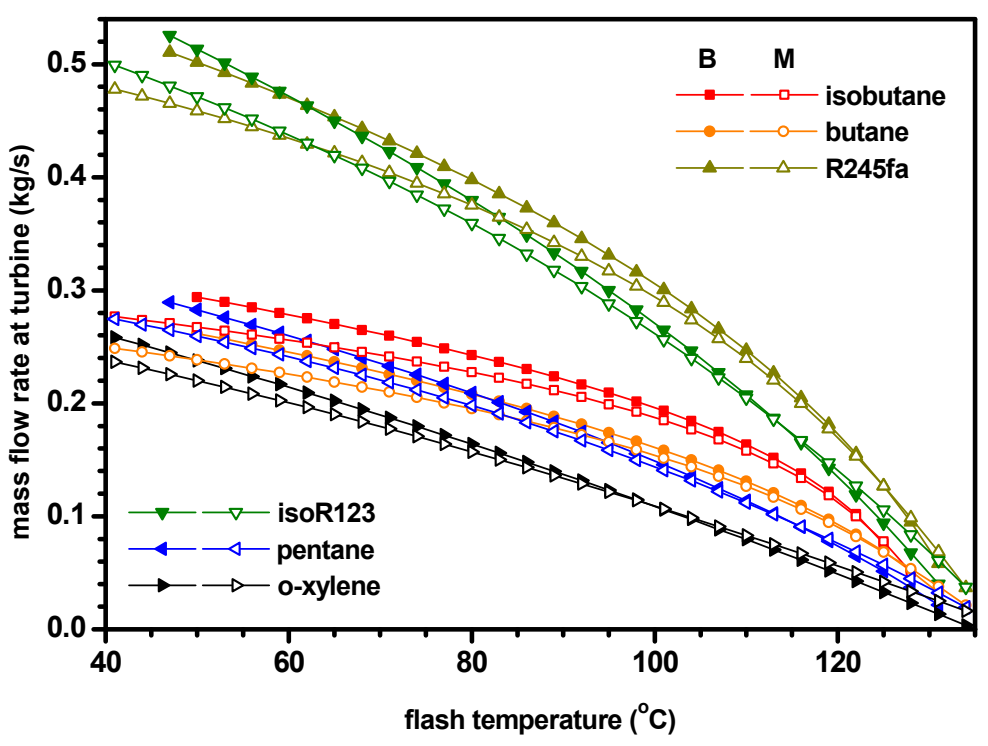

(b)

Figure 4. Effect of the flash temperature on the mass flow rates in the heater and turbine. (a) mass flow rate at heater; (b) mass flow rate at turbine.

Consequently, the temperature of the working fluid entering heater $T_{4}$ increased, but at the same time, the temperature of the source leaving the heater $T_{11}$ also increased. If the pinch point occurred at the heater inlet for the working fluid, $T_{11}=T_{4}+\Delta T_{p p}$ (in this work, the pinch point position was determined using iterative calculations such that the minimum temperature difference reached the prescribed pinch temperature difference $\Delta T_{p p}$. In Reference [29], for example, it was assumed that the pinch point occurred at the heater inlet for the working fluid, so $T_{11}=T_{4}+\Delta T_{p p}$ always for both the cycles with and without regeneration. If the pinch point occurred at another point due to the nonlinear profiles near the critical point of working fluid, the relation became more complex. It can be seen from Equation (1) of $m_{5}=c_{p s}\left(T_{10}-T_{11}\right) /\left(h_{5}-h_{4}\right)$, the former acted as an increasing factor and the latter had a decreasing factor for the mass flow rate. All the quality in flash evaporator, $h_{5}-h_{4}$, and $T_{10}-$ $T_{11}$ decrease concavely with increasing flash temperature; therefore, the decreasing rate of the variables became greater as the flash temperature increased. The first two terms approached to zero but the third term did not when the flash temperature approached the heating temperature as $T_{H}-T_{F} \rightarrow 0$. For a specified flash temperature, the mass flow rate was the lowest with butane and isobutane, and the highest with R123. In both OFCB and OFCM, an increment of flash temperature led to a decrease of mass flow rate at the turbine. This was because an increase of the flash temperature led to a decrease of the pressure difference during expansion in the expansion valve or TPE, and consequently a decrease of the quality in the flash evaporator. With a given flash temperature, the mass flow rate in the OFCM was lower than that in the OFCB since the fluid quality in the flash evaporator resulting from the expansion through TPE in OFC was lower than the quality resulting from the throttle expansion in the OFCB. In both the OFCB and OFCM, the mass flow rate was the largest when the working fluid was R245fa and the smallest when it was o-xylene.

Figure 5 shows the effects of the flash temperature on the heat and exergy input rates of the system. In the $\mathrm{OFCB}$, each of the input rates remained almost constant, even with the flash temperature changes, due to the almost constant temperature of fluid entering the heater, and in turn, an almost constant temperature of the source fluid leaving the heater. In OFCM, an increment of the flash temperature causes the heat and exergy input rates to fall. It is because an increment of flash temperature decreased the fluid quality in the flash evaporator, which enhanced the regeneration effect and consequently increased the fluid temperature entering the heater. The working fluid leading to the highest input 
rate was o-xylene in the OFCB and R245fa in the OFCM, while the working fluid leading to the lowest input rate was butane in the OFCB and o-xylene in the OFCM.

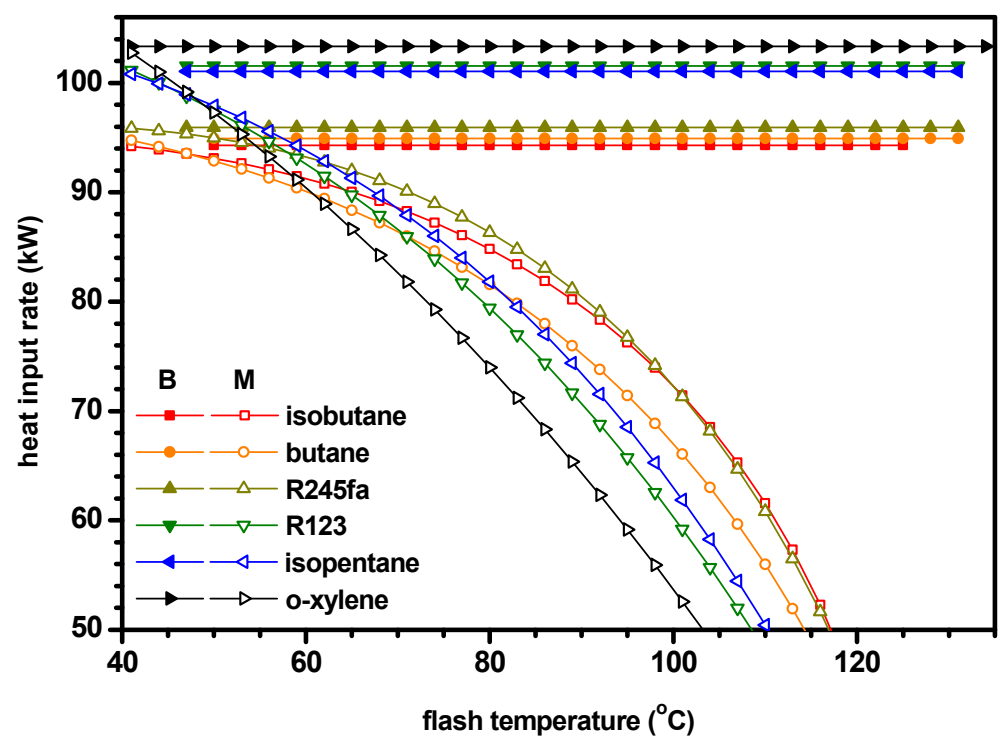

(a)

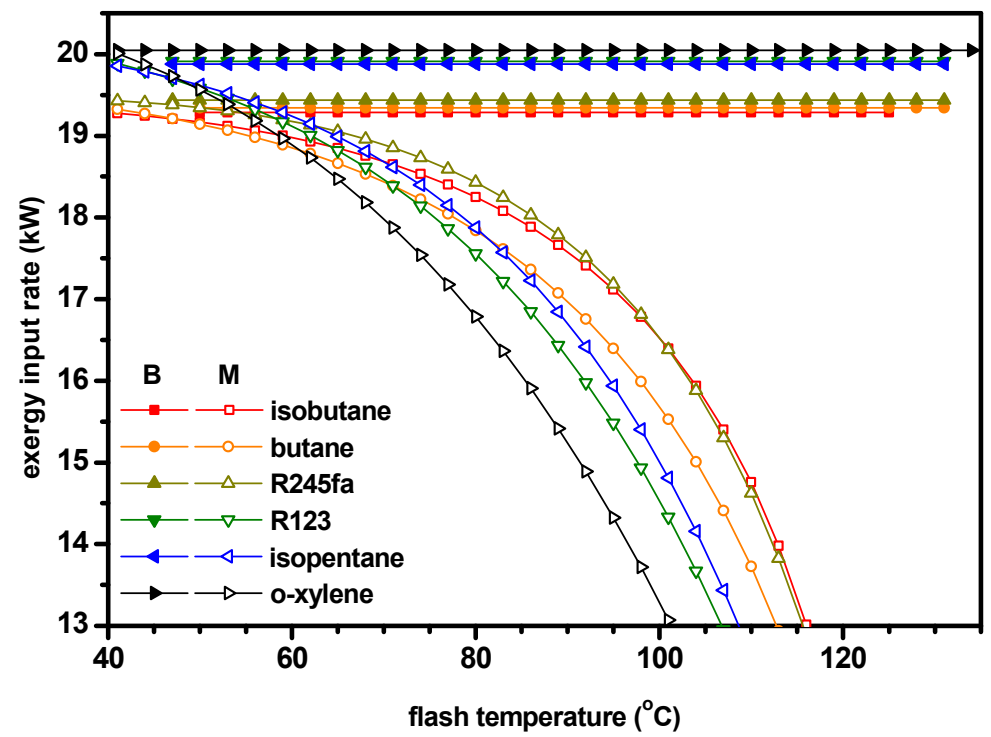

(b)

Figure 5. Effect of the flash temperature on the heat and exergy input. (a) heat input rate; (b) exergy input rate.

Figure 6 shows the effects of the flash temperature on the power productions of the turbine and TPE. It is to be noted that the turbine power had a maximum value with respect to the flash temperature. This is because with an increase of the flash temperature, the specific turbine work becomes higher according to the increased pressure difference across the turbine, whereas the mass flow rate at the turbine decreases. The maximum turbine power of OFCB was greater than OFCM. On the other hand, an increase of the flash temperature led to a decrease of the power of the TPE due to the decreased pressure ratio of TPE. It is to be noted that the turbine and TPE powers were the highest with butane and the lowest with o-xylene. 


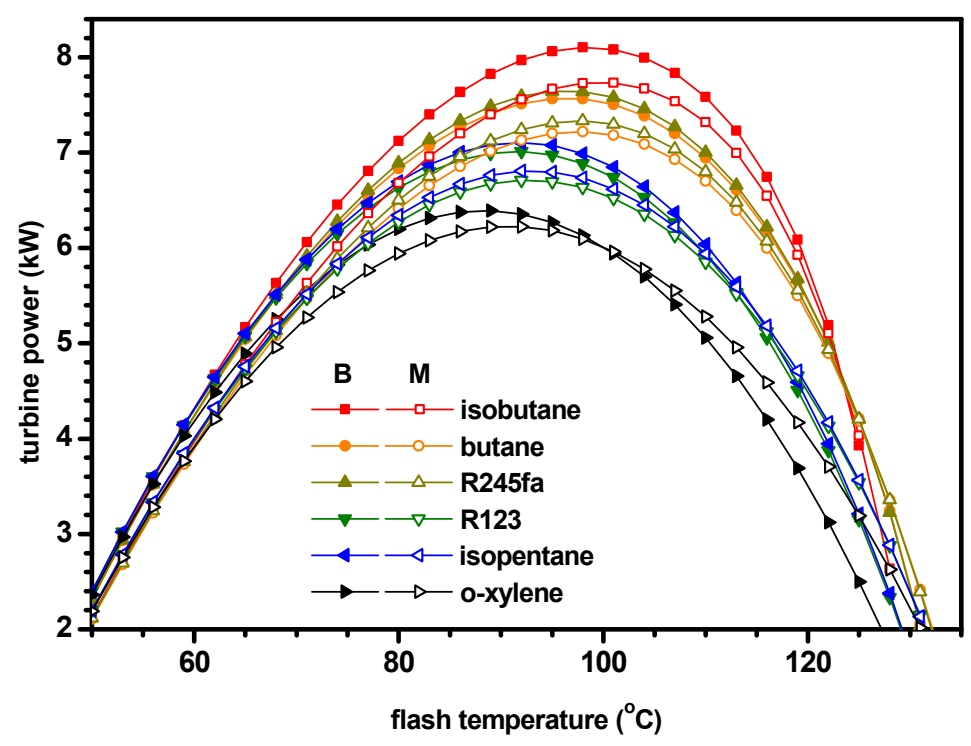

(a)

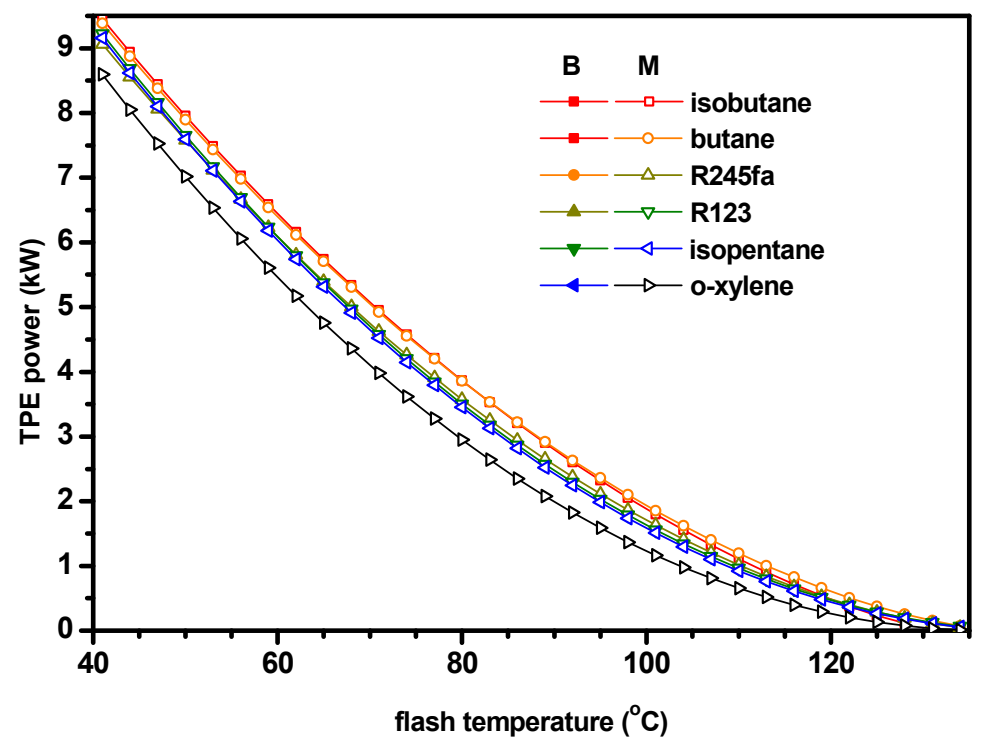

(b)

Figure 6. Effect of the flash temperature on the powers of the turbine and two-phase expander. (a) turbine power; (b) TPE power.

Figure 7 displays the influence of flash temperature on the pump and system powers. The pump power of the OFCB remained almost constant even as the flash temperature changed since the temperature and mass flow rate at the pump inlet were almost constant. In the OFCM, however, an increment of the flash temperature caused a decrease of pump power. This can be explained as follows. The pump power is made up of powers from pump 1 and pump 2. When the flash temperature becomes higher, the power of pump 1 decreases according to the decreased mass flow rate, and the power of pump 2 also decreases due to the increase of the inlet pressure and consequent decrease of the pressure ratio of pump 2. The net power of the system had a local maximum value with respect to the flash temperature in both the OFCB and the OFCM, and the maximum net power of the OFCM was larger than that of the OFCB. The flash temperatures for the maximum net power of the OFCM were lower than those of the $\mathrm{OFCB}$, because the flash temperature for the maximum turbine power of 
the OFCM was similar to that of the OFCB, but the power of the TPE decreased with increasing flash temperature. The powers of the turbine, pump, and TPE of the OFCB and OFCM were the highest when the working fluid was butane and the lowest when it was o-xylene, However, the net power in the OFCM was the highest with o-xylene and the lowest with butane, while the net power of the OFCB was the highest with R123 and the lowest with isobutane.

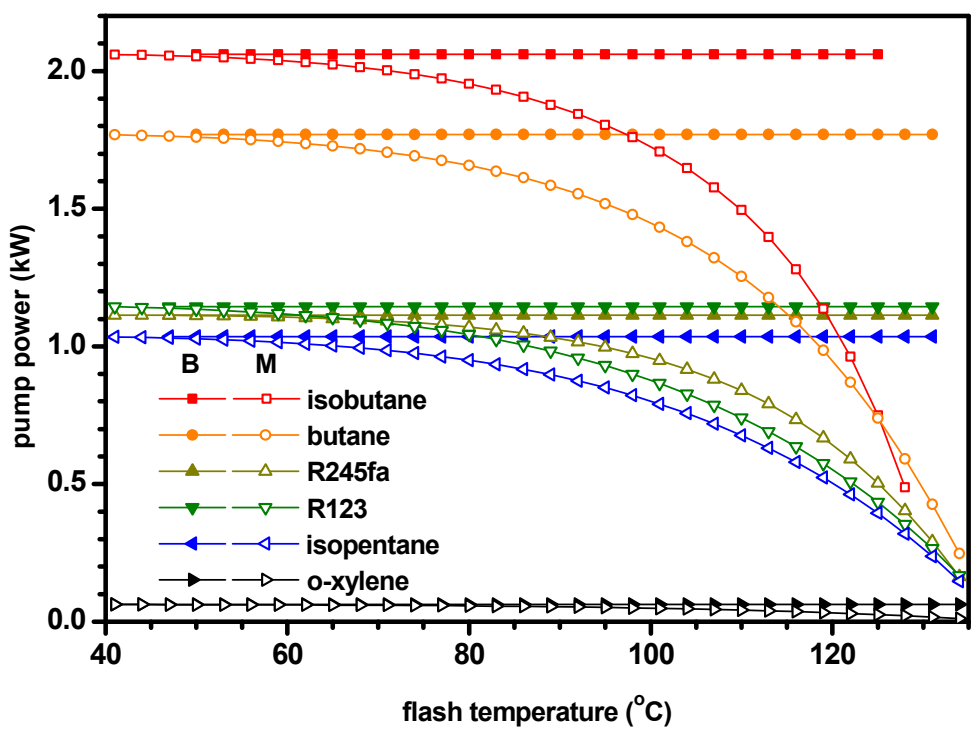

(a)

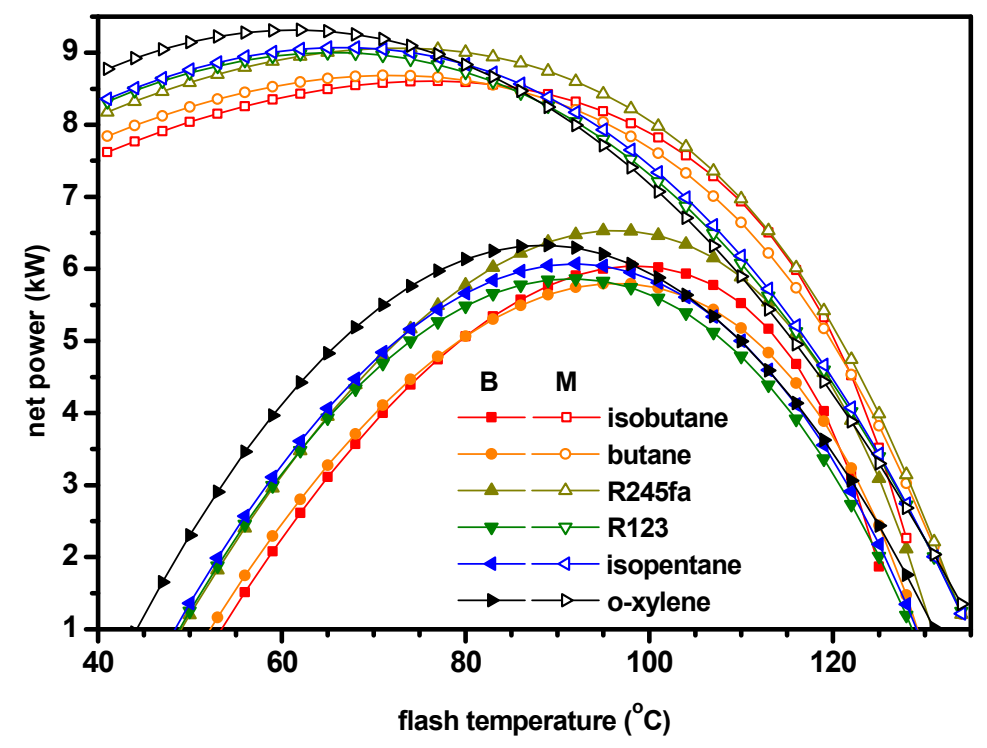

(b)

Figure 7. Effect of the flash temperature on the pump power and net power production. (a) pump power; (b) net power.

Figure 8 illustrates the influence of the flash temperature on the thermal and second-law efficiencies. The thermal efficiency showed a local maximum with respect to the flash temperature in the OFCB, while it simply increased with flash temperature in the OFCM. Meanwhile, the second-law efficiency had a peak with respect to the flash temperature in both the OFCB and OFCM. It should be noted that for a given flash temperature, each of the thermal and second-law efficiencies of OFCM 
were much higher than that of the OFCB. In the OFCB, R245fa and R123 showed the best and worst performances of the thermal and second-law efficiencies. In the OFCB, however, o-xylene and butane showed the best and worst performances of the thermal and second-law efficiencies.

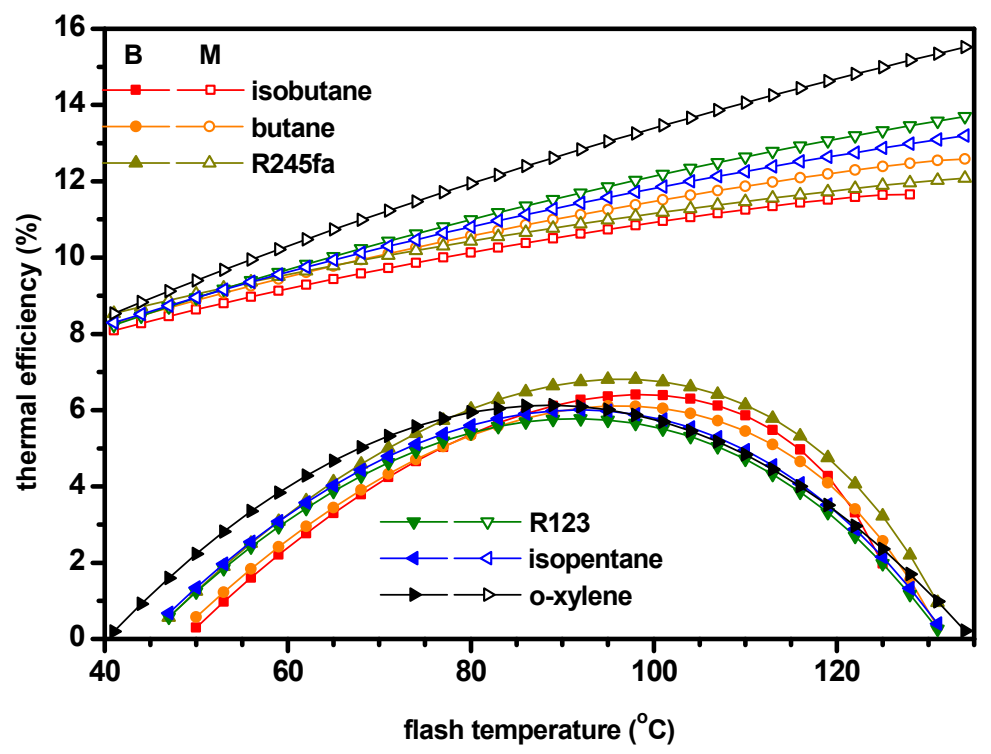

(a)

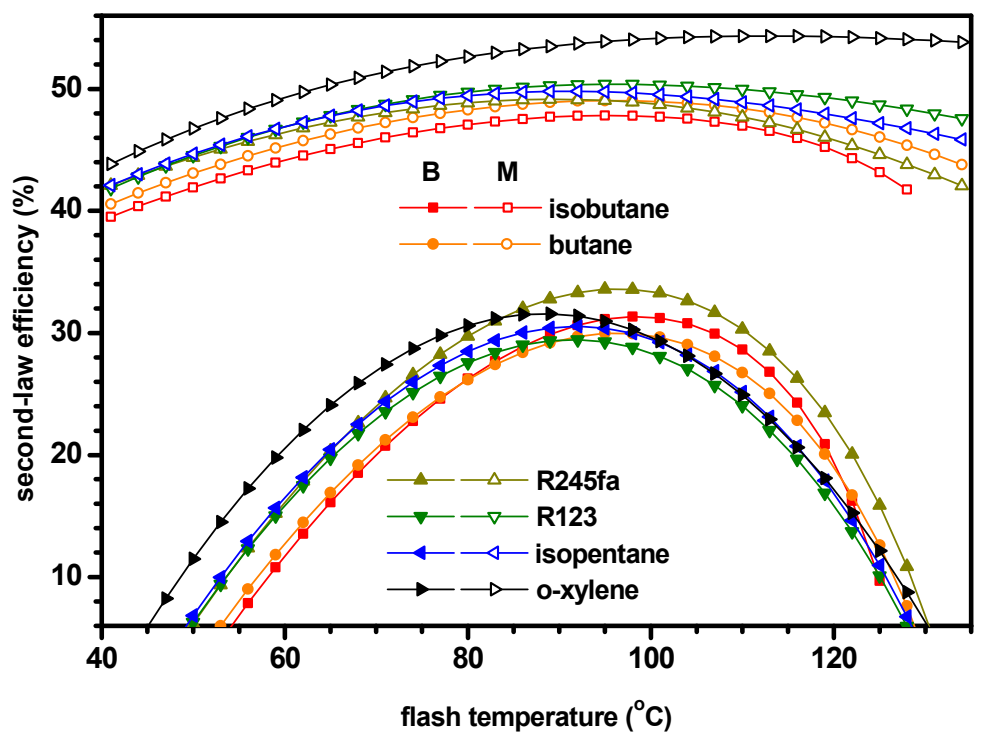

(b)

Figure 8. Effect of the flash temperature on the thermal and second-law efficiencies. (a) thermal efficiency; (b) second-law efficiency.

Figure 9 shows the influence of the flash temperature on the pressure ratio of the turbine, and the specific volume flow rate defined as the volume flow rate of fluid leaving turbine required to produce $1 \mathrm{~kW}$ of net power. In the OFCM, as previously mentioned, o-xylene led to the highest net power, thermal efficiency, and second-law efficiency. However, o-xylene led to highest pressure ratio and specific volume flow rate, which would cause a lot of investment costs. 


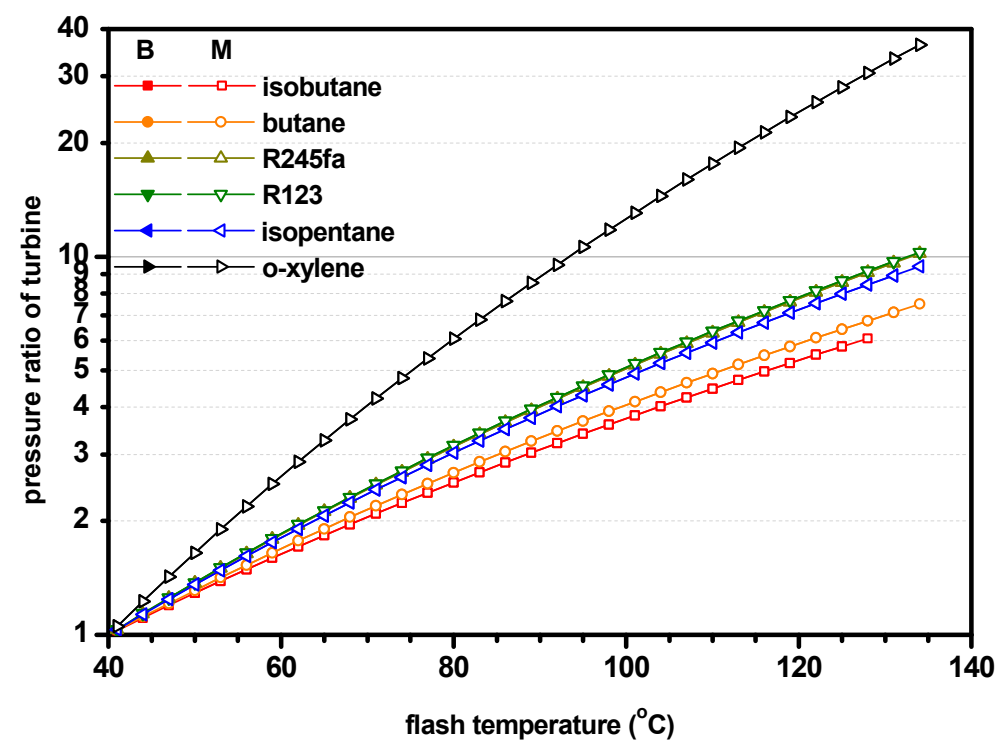

(a)

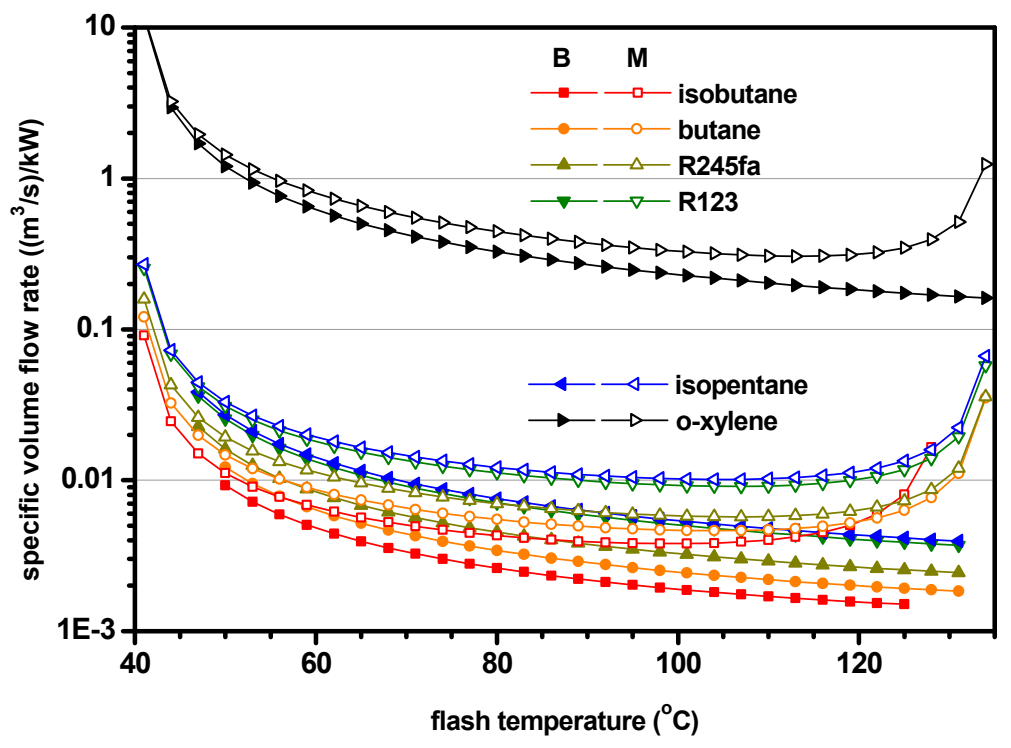

(b)

Figure 9. Effect of the flash temperature on the pressure ratio and specific volume flow rate. (a) pressure ratio of turbine; (b) specific volume flow rate.

\subsection{Effects of Source under Optimal Conditions of the Flash Temperature}

In this section, the effects of the source temperature on the performances of the OFCB and OFCM are studied under the conditions of the optimal flash temperature for the maximum second-law efficiency.

Figures 10 and 11 show the temperature profiles of fluids in the heater and condenser in the OFCB and OFCM, respectively, for source temperatures of $T_{S}=150{ }^{\circ} \mathrm{C}, 190{ }^{\circ} \mathrm{C}, 230^{\circ} \mathrm{C}$, and $270{ }^{\circ} \mathrm{C}$ with R123 whose critical temperature is $183.75^{\circ} \mathrm{C}$. The pinch points were located at the heater inlet for the working fluid, namely $H=0$; when the source temperature was $190^{\circ} \mathrm{C}$, the pinch point occurred at $H$ $=0.68$; and the temperature difference at $H=0$ was $21.7^{\circ} \mathrm{C}$. This happened according to the nonlinear temperature profile of saturated-liquid working fluid when the heating temperature is near the critical temperature of the working fluid. This means that if it is assumed that the pinch point occurs at heat 
inlet of working fluid always, the minimum temperature between the hot and cold streams in the heat exchanger becomes negative, which is impossible to operate. Therefore, the operation with a top cycle temperature near the critical temperature should be avoided to reduce the risk of instability caused by strong variations of thermodynamic properties with temperature and modification of the pinch point position $[29,35]$.

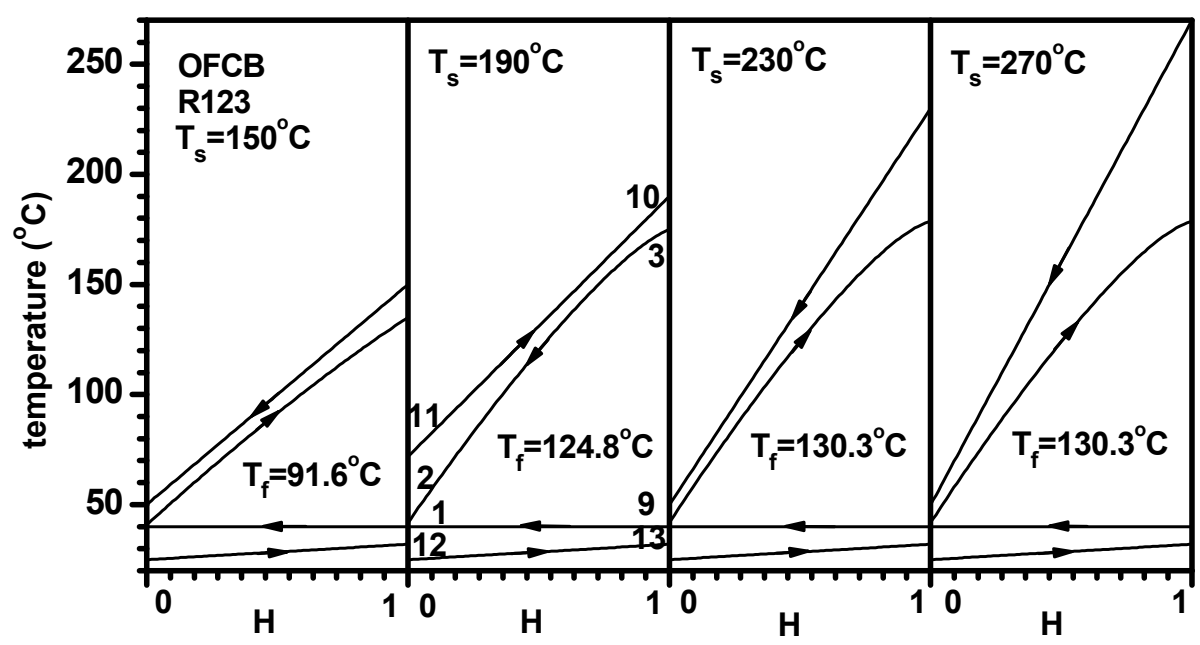

Figure 10. Temperature distributions in the heater and condenser in the OFCB.

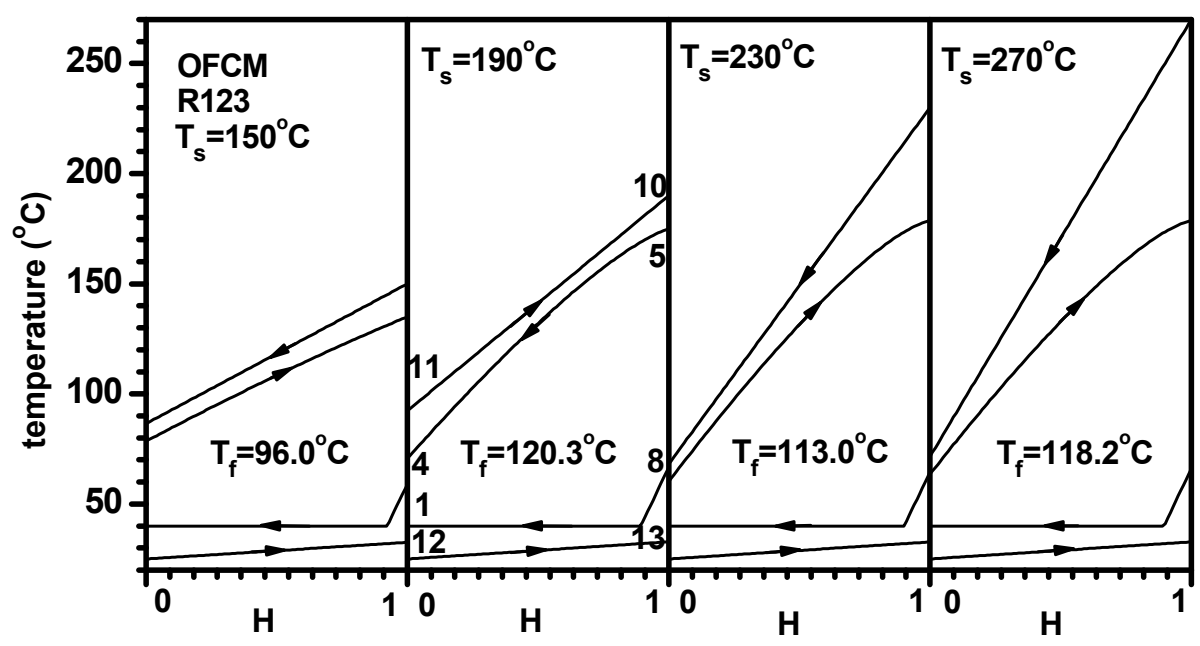

Figure 11. Temperature distributions in the heater and condenser in the OFCM.

Figure 12 represents the influence of the source temperature on the optimum flash temperature for the maximum second-law efficiency, and the quality of fluid in the flash evaporator under the optimal conditions. In the OFCB, the optimum flash temperature first increased with an increase of the source temperature, and then remained constant after $T_{S}-15>T_{c r}-10$ from Equation (13). In the OFCM, the optimum flash temperatures showed complex behaviors in the vicinity of the critical point since an elevated temperature of the fluid at the heater inlet caused significant effects due to a nonlinear temperature profile on the performance of the optimum flash temperature. The quality first increased and then remained constant with increasing source temperature in the OFCB, while it had a maximum value with respect to the source temperature in the OFCM except for the case of o-xylene. The quality increased monotonically with source temperature when o-xylene was used. 


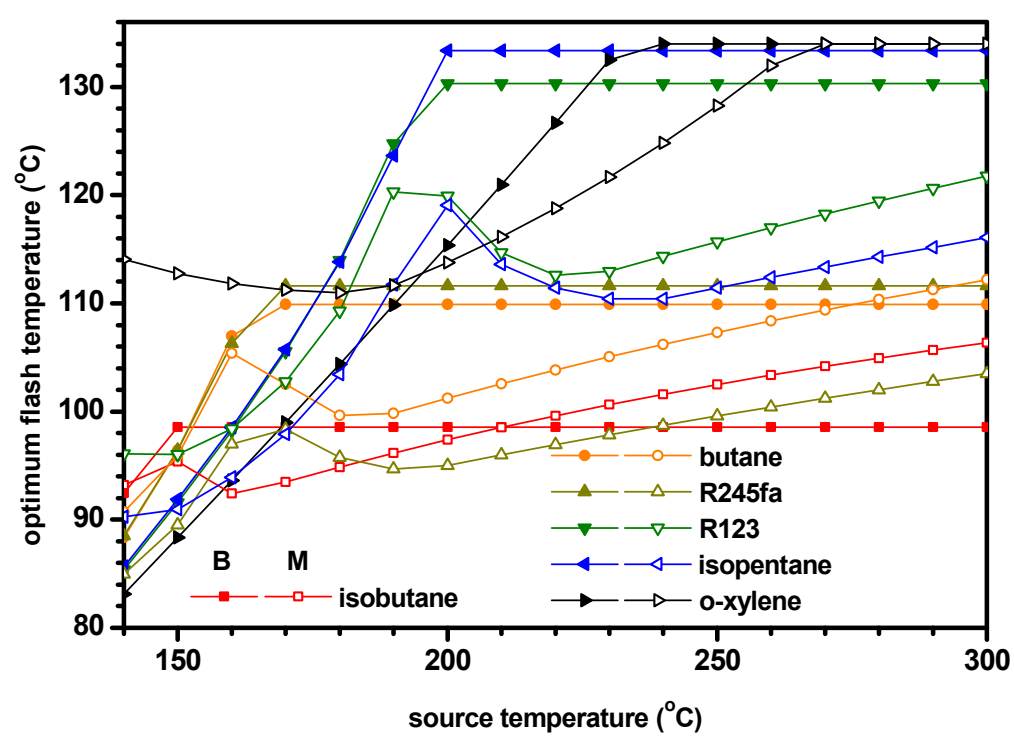

(a)

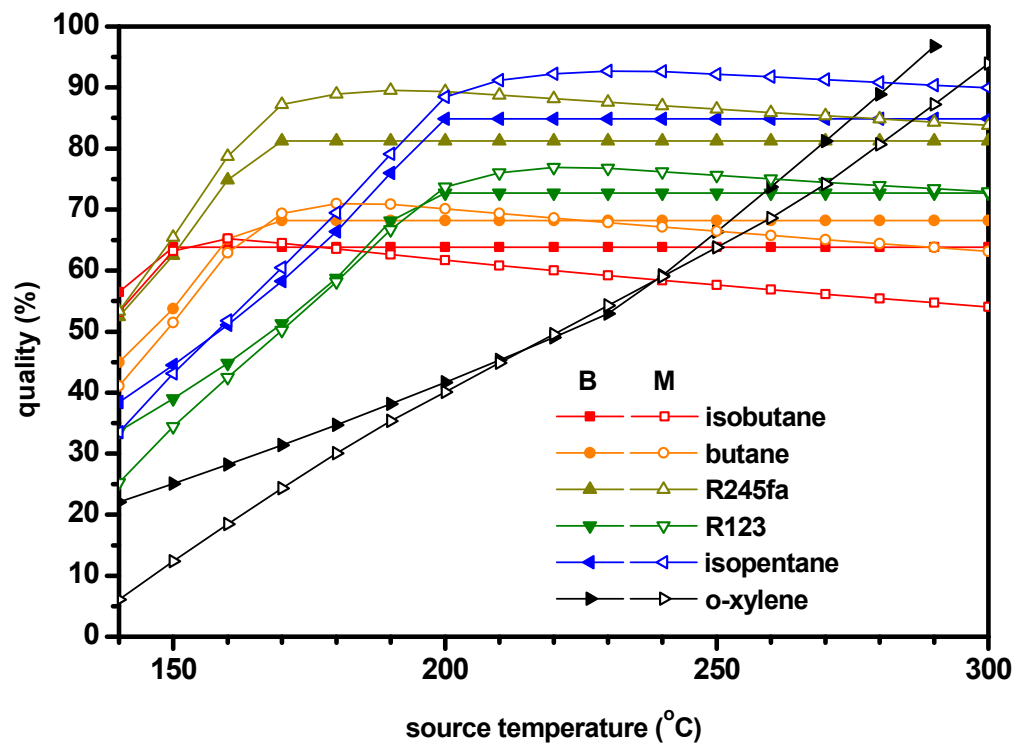

(b)

Figure 12. Effect of the source temperature on the optimum flash temperature and dryness factor in the flash evaporator. (a) optimum flash temperature; (b) quality.

Figure 13 displays the influence of the source temperature on the mass flow rates at the heater and turbine. In both the OFCB and OFCM, as the source temperature increased, the mass flow rate at the heater first decreased before the heating temperature was fixed and then abruptly increased, thus it showed a sharp minimum value, except for the case of o-xylene which led to a simple decrease of the mass flow rate with increasing source temperature [22]. The mass flow rate was the largest when the working fluid was R123. The mass flow rate at the turbine simply increased with the increase of the source temperature in both the OFCB and OFCM. The mass flow rate was the largest when the working fluid was R245fa and the smallest when it was o-xylene. 


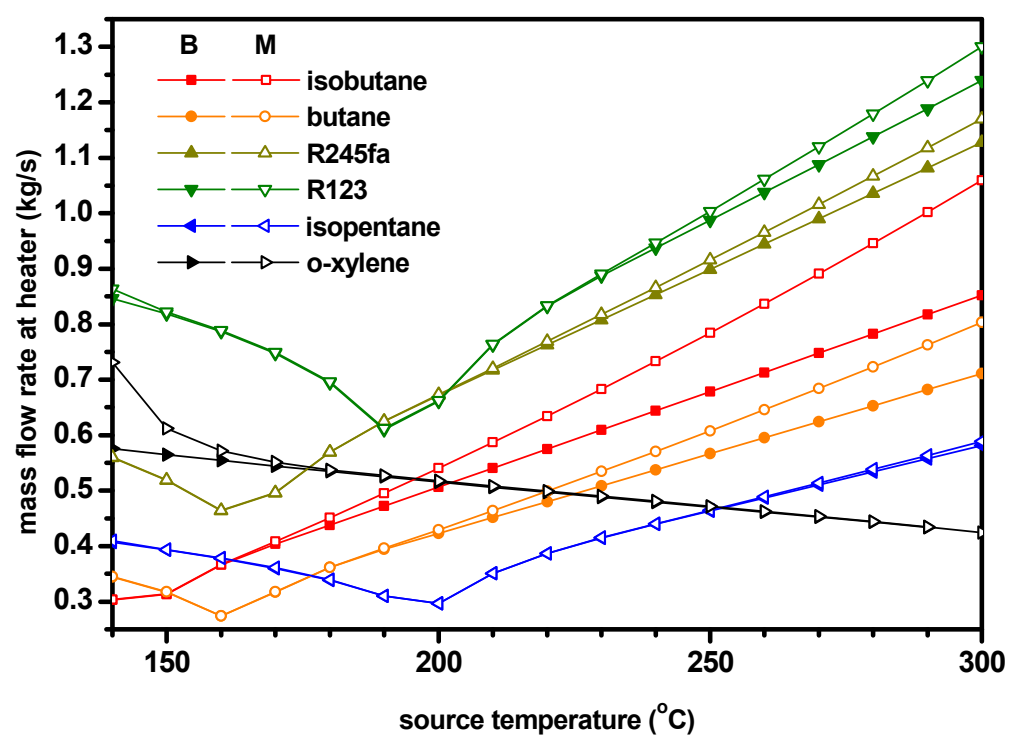

(a)

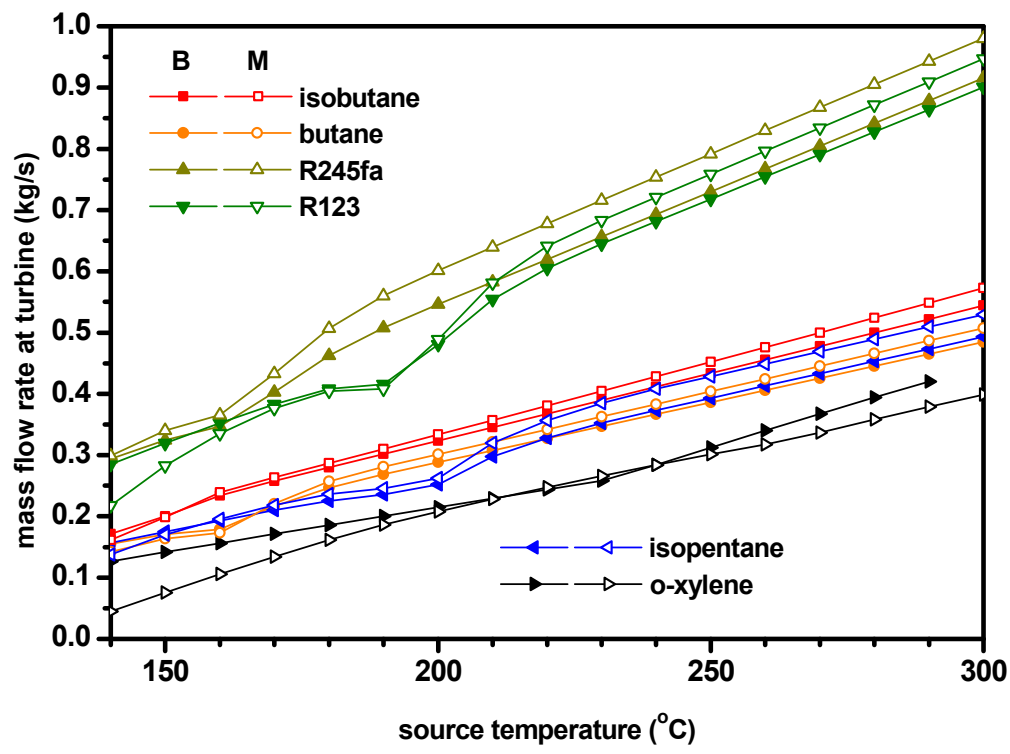

(b)

Figure 13. Effect of the source temperature on the mass flow rates in the heater and turbine. (a) mass flow rate at heater; (b) mass flow rate at turbine.

Figure 14 demonstrates the effects of source temperature on the turbine and net powers. Both the turbine and net powers in the OFCB and ODCM increased with source temperature. In both the OFCB and OFCM, as the source temperature increased, the working leading to the highest turbine power varied from butane to o-xylene; however, the working fluid leading to the highest net power was o-xylene. For a specified source temperature and working fluid, the turbine power of the OFCM would be higher or lower than the OFCB depending on the source temperature, but the net power of the OFCM was always higher than that of the OFCB irrespective of the source temperature. 


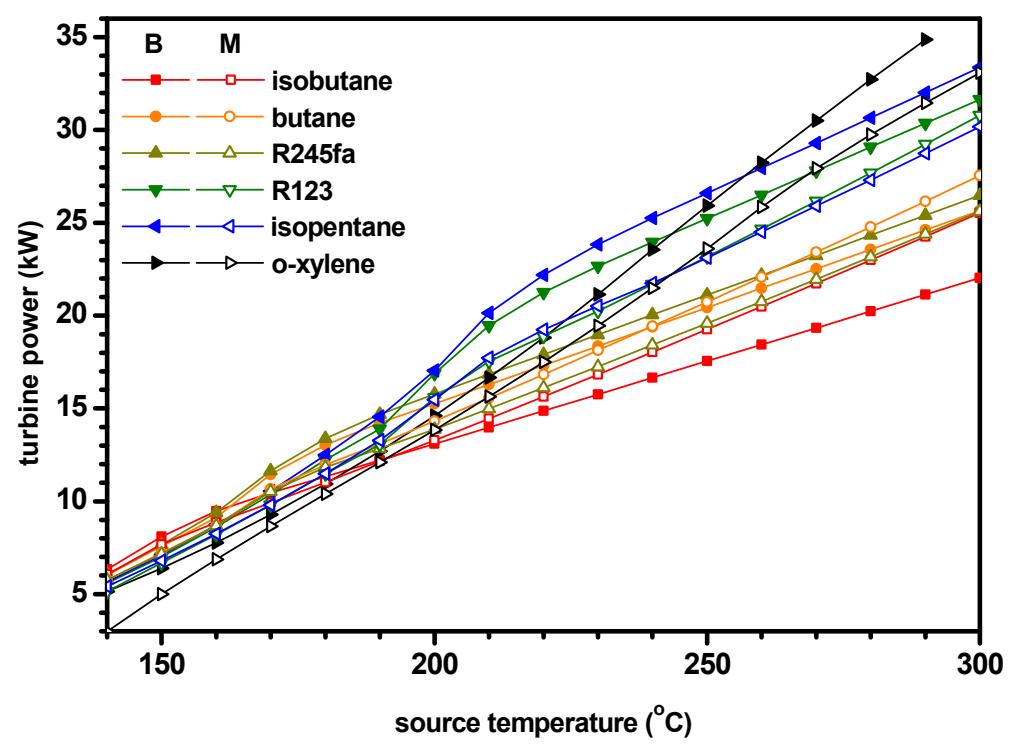

(a)

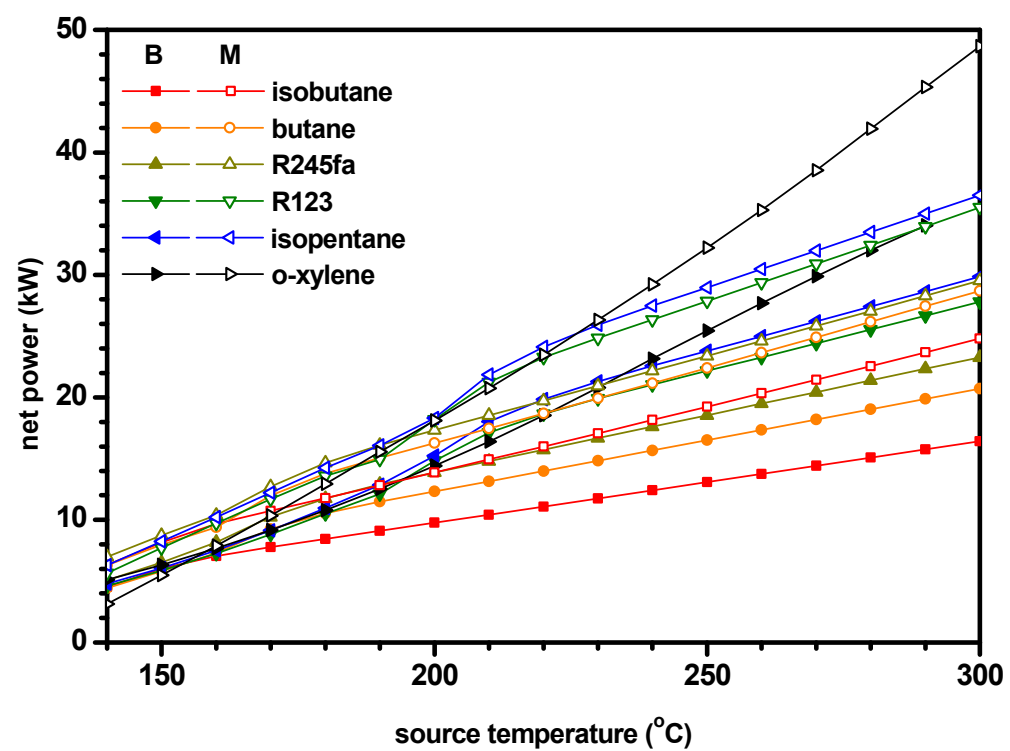

(b)

Figure 14. Effect of the source temperature on the mass flow rates in the heater and turbine. (a) turbine power; (b) net power.

Figure 15 shows the influence of the source temperature on the thermal and second-law efficiencies under the optimal conditions of the flash temperature. In both the OFCB and OFCM, each of the thermal and second-law efficiencies first increased and then remained constant or almost constant or decreased with increasing source temperature except the case of o-xylene, which simply led to an increasing efficiency. In the OFCB, the working fluid leading the highest thermal or second-law efficiency varied depending on the source temperature as it was $\mathrm{R} 245 \mathrm{fa}$ up $180^{\circ} \mathrm{C}$, isopentane up to $230{ }^{\circ} \mathrm{C}$, and o-xylene up to $300^{\circ} \mathrm{C}$. In the OFCM, however, the best working fluid was always o-xylene, followed by R123 and isopentane. For a given source temperature, the thermal and second-law efficiencies of OFCM were always much higher than those of the OFCB. 


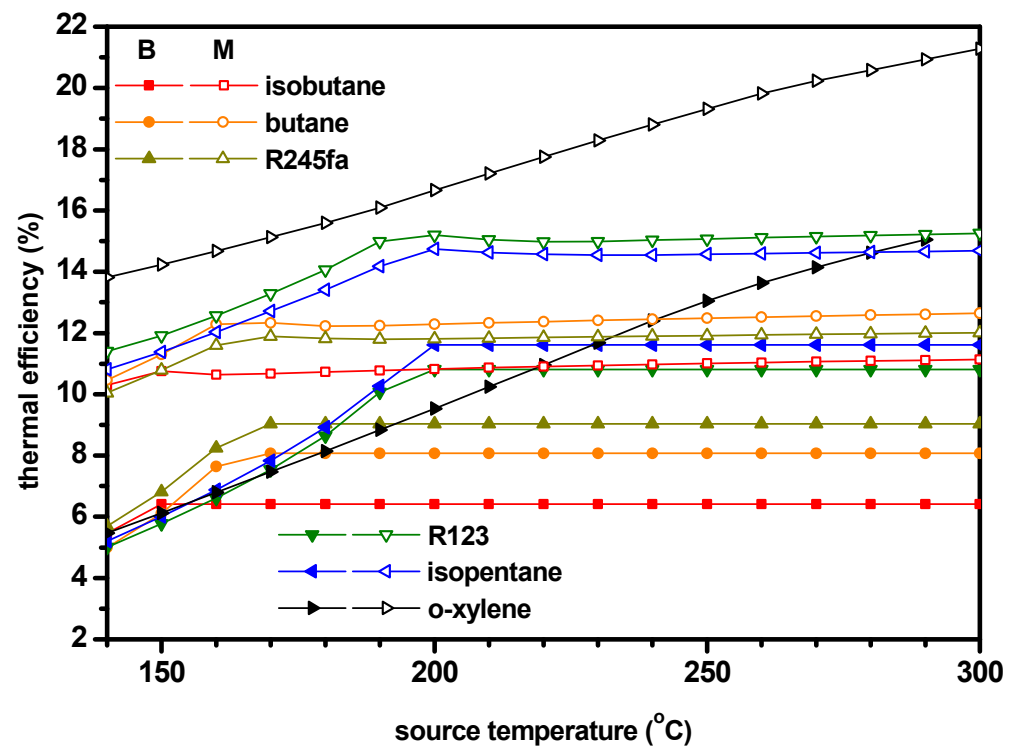

(a)

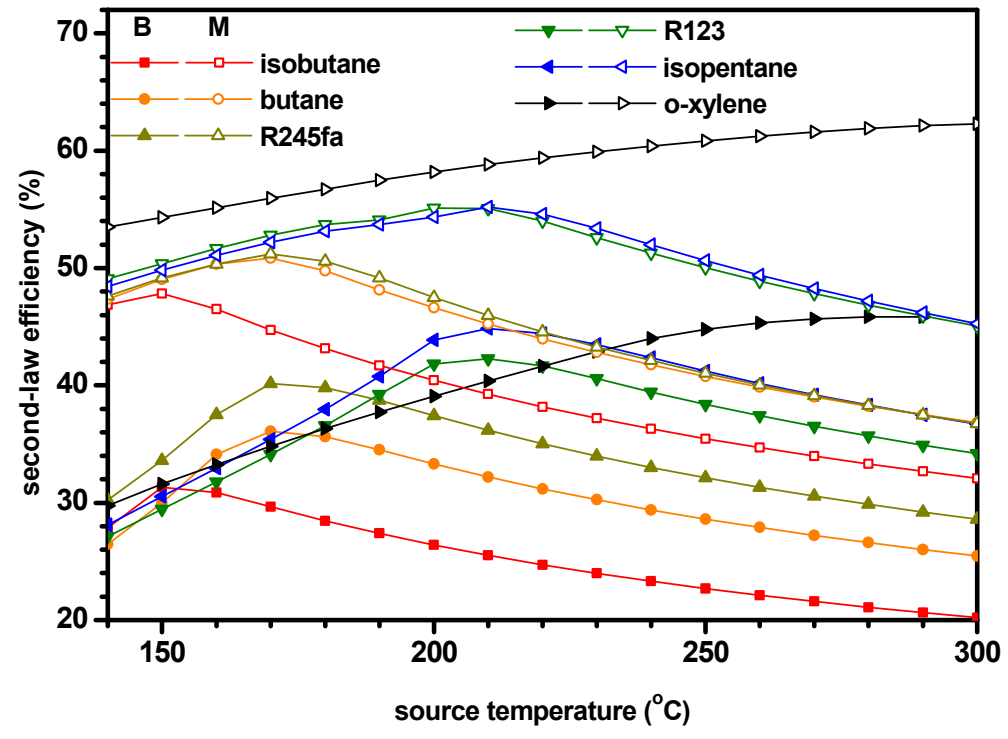

(b)

Figure 15. Effect of the source temperature on the thermal and second-law efficiencies. (a) thermal efficiency; (b) second-law efficiency.

Figure 16 demonstrates the influence of the source temperature on the pressure ratio of the turbine and specific volume flow rate to generate $1 \mathrm{~kW}$ of net power. The higher pressure ratio and specific volume flow rate would cause a higher cost of the system. As mentioned above, among the considered working fluids, o-xylene was the optimum fluid for the highest net power, thermal efficiency, and second-law efficiency when used. However, o-xylene would require a much higher pressure ratio and specific volume rate than other working fluids. This means that it was necessary to consider the characteristics of the pressure ratio and the specific volume flow rate, as well as the net power and the thermal and second-law efficiencies. Considering environmental situations for R123, isopentane is recommended as the most suitable working fluid for the OFCM. 


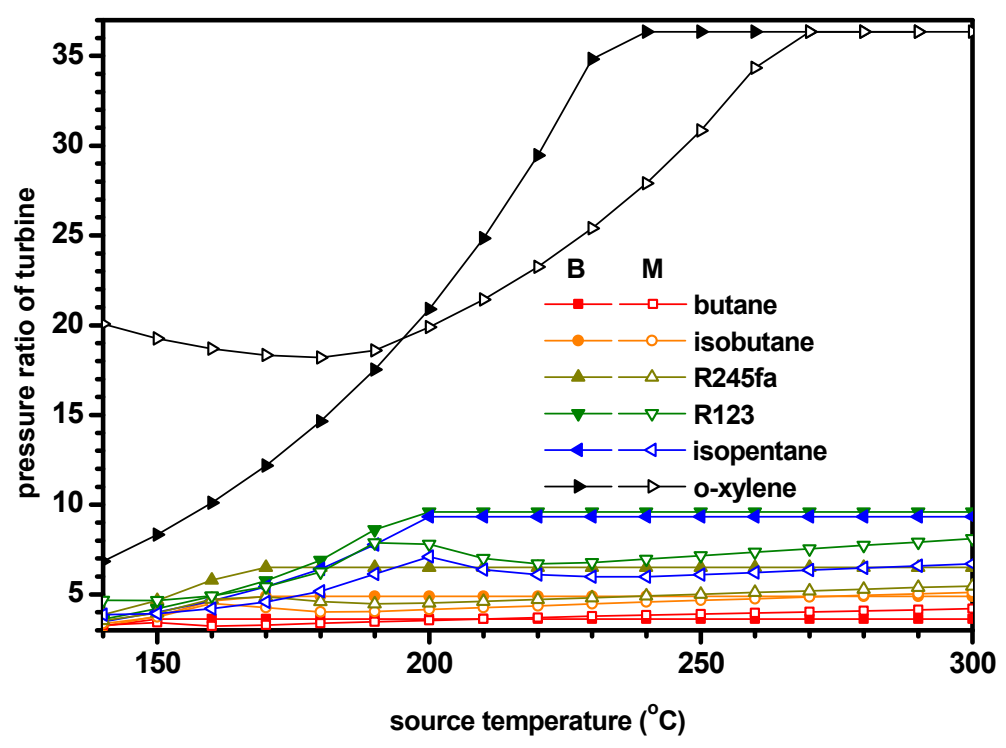

(a)

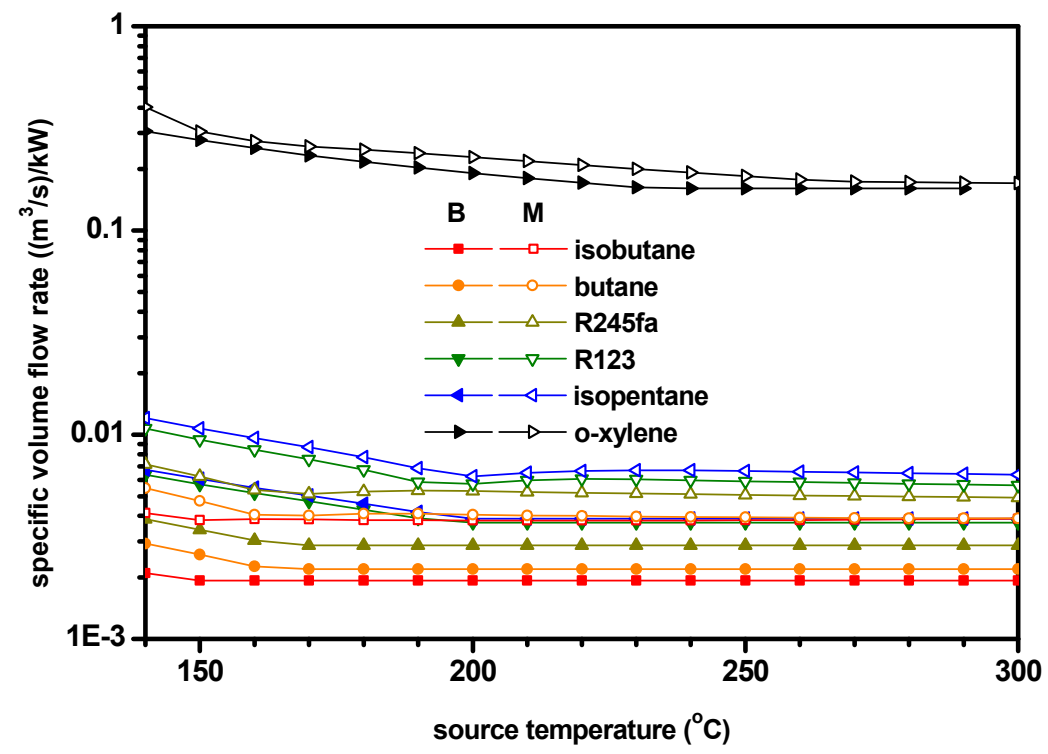

(b)

Figure 16. Effect of the source temperature on the pressure ratio and specific volume flow rate. (a) pressure ratio of turbine; (b) specific volume flow rate.

\section{Conclusions}

In this work, a modified organic flash cycle (OFCM) was proposed, and a thermodynamic and optimal analysis was comparatively presented on the performances of the OFCB and OFCM. By taking each of six substances as the working fluid and the flash and source temperatures as key parameters for both cycles, a parametric study was carried out. The important findings are the following:

1. The temperature distribution profiles of streams in the heater and condenser of the OFCB and OFCM were comparatively studied for different flash and source temperatures. In the OFCM, the nonlinear temperature profile had a great influence on the pinch-point position and thermodynamic performance of the system due to the elevated temperature of the working fluid 
entering the heater, especially when the source temperature was near the critical temperature of the working fluid.

2. The thermal efficiency had a maximum value with respect to the flash temperature in the OFCB, but simply increased with flash temperature in the OFCM. The net power and the second-law efficiency had a maximum value with respect to the flash temperature in both the OFCB and OFCM. For a specified flash temperature, all the net power, thermal, and second-law efficiencies of the OFCM were higher than those of the OFCB.

3. Thermodynamic performances were investigated for source temperatures from $140{ }^{\circ} \mathrm{C}$ to $300^{\circ} \mathrm{C}$ under the optimal conditions of the flash temperature for the maximum second-law efficiency. The optimum flash temperature first increased with an increase in the source temperature and then remained constant in the OFCB, while showing complex behavior near the critical point of the working fluid in the OFCM.

4. The net power production of the system increased with source temperature in both the OFCB and OFCM, and the net power in the OFCM was greater than that in the OFCB, due to power generation by TPE. The thermal and second-law efficiencies of the OFCM were superior to the $\mathrm{OFCB}$, mainly due to regeneration.

5. The pressure ratio and specific volume flow rate were investigated for different source temperatures and working fluids, and it was shown that o-xylene led to a significantly higher pressure ratio and specific volume flow rate.

6. The working fluid that carried the highest second-law efficiency under optimum conditions varied according to the source temperature in the OFCB, while it was always o-xylene followed by R123 and isopentane in the OFCM. However, according to the very high pressure ratio and specific volume flow rate of a system using o-xylene, and the environmental effect of R123, isopentane is recommended as the most suitable working fluid for an OFCM.

Acknowledgments: This research was supported by the Basic Science Research Program through the National Research Foundation of Korea (NRF) funded by the Ministry of Education, Science and Technology (NRF-2016R1D1A1B03935888, NRF-2018R1D1A1B07048866).

Conflicts of Interest: The author declare no conflict of interest.

\section{Nomenclature}

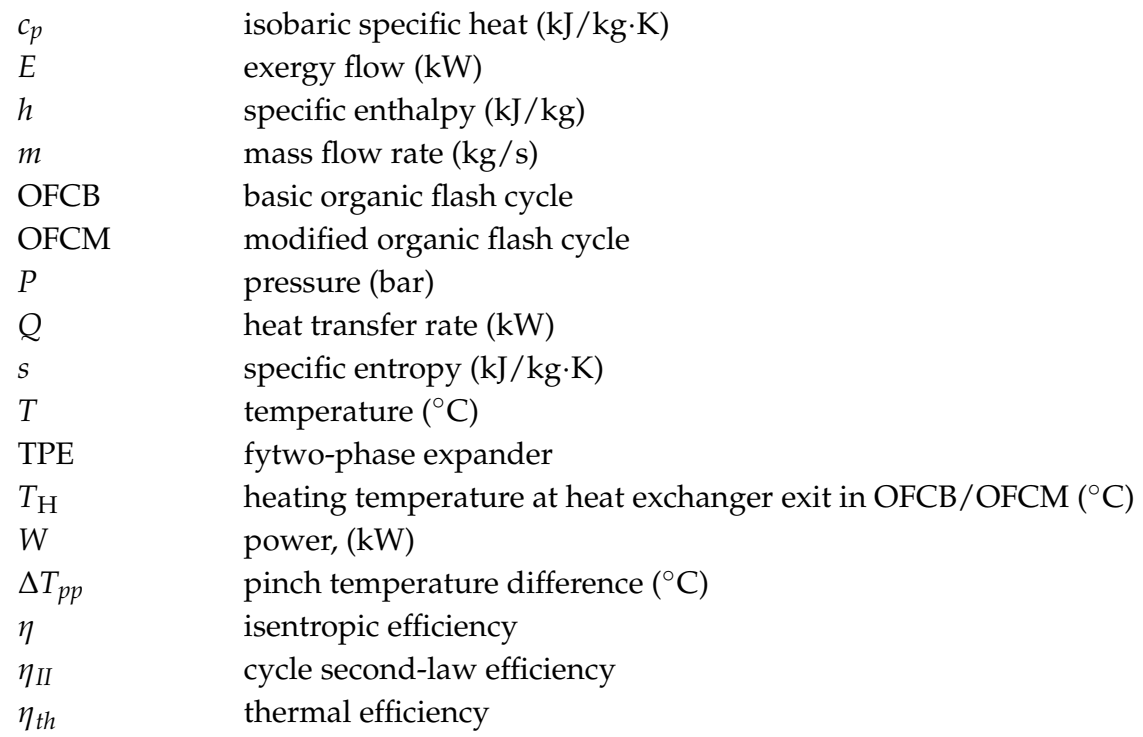




\section{Subscripts}

$\begin{array}{ll}0 & \text { dead state } \\ C & \text { compressor/coolant } \\ c r & \text { critical } \\ F & \text { flash } \\ H & \text { high } \\ L & \text { low/condensation } \\ p & \text { pump } \\ S & \text { source } \\ t & \text { turbine } \\ w & \text { working fluid }\end{array}$

\section{References}

1. Aghahosseini, A.; Dincer, I. Comparative performance analysis of low-temperature Organic Rankine Cycle (ORC) using pure and zeotropic working fluids. Appl. Therm. Eng. 2013, 54, 35-42. [CrossRef]

2. Tchanche, B.F.; Pétrissans, M.; Papadakis, G. Heat resources and organic Rankine cycle machines. Renew. Sustain. Energy Rev. 2014, 39, 1185-1199. [CrossRef]

3. Tchanche, B.F.; Papadakis, G.; Lambrinos, G.; Frangoudakis, A. Fluid selection for a low-temperature solar organic Rankine cycle. Appl. Therm. Eng. 2009, 29, 2468-2476. [CrossRef]

4. Li, G. Organic Rankine cycle performance evaluation and thermoeconomic assessment with various applications part I: Energy and exergy performance evaluation. Renew. Sustain. Energy Rev. 2016, 53, 477-499. [CrossRef]

5. Mansoury, M.; Jafarmadar, S.; Khalilarya, S. Energetic and exergetic assessment of a two-stage Organic Rankine Cycle with reactivity controlled compression ignition engine as a low temperature heat source. Energy Convers. Mgmt. 2018, 166, 215-232. [CrossRef]

6. Kim, K.H.; Perez-Blanco, H. Performance Analysis of a Combined Organic Rankine Cycle and Vapor Compression Cycle for Power and Refrigeration Cogeneration. Appl. Therm. Eng. 2015, 91, 964-974. [CrossRef]

7. Kim, K.H.; Kim, K.C. Thermodynamic performance analysis of a combined power cycle using low grade heat source and LNG cold energy. Appl. Therm. Eng. 2014, 70, 50-60. [CrossRef]

8. Yao, E.; Wang, H.; Wang, L.; Xi, G.; Maréchal, F. Multi-objective optimization and exergoeconomic analysis of a combined cooling, heating and power based compressed air energy storage system. Energy Convers. Manag. 2017, 138, 199-209. [CrossRef]

9. Li, J.; Alvi, J.Z.; Pei, G.; Ji, J.; Li, P.; Huide, F. Effect of working fluids on the performance of a novel direct vapor generation solar organic Rankine cycle system. Appl. Therm. Eng. 2016, 98, 786-797. [CrossRef]

10. Bao, J.; Zhao, L. A review of working fluid and expander selections for organic Rankine cycle. Renew. Sustain. Energy Rev. 2013, 24, 325-342. [CrossRef]

11. Lecompte, S.; Huisseune, H.; van den Broek, M.; Vanslambrouck, B.; De Paepe, M. Review of organic Rankine cycle (ORC) architectures for waste heat recovery. Renew. Sustain. Energy Rev. 2015, 47, 448-461. [CrossRef]

12. Pethurajan, V.; Sivan, S.; Joy, G.C. Issues, comparisons, turbine selections and applications-An overview in organic Rankine cycle. Energy Convers. Mgmt. 2018, 166, 474-488. [CrossRef]

13. Mahmoudi, A.; Fazli, M.; Morad, M.R. A recent review of waste heat recovery by Organic Rankine Cycle. Appl. Therm. Eng. 2018, 143, 660-675. [CrossRef]

14. Shi, L.; Shu, G.; Tian, H.; Deng, S. A review of modified Organic Rankine Cycles (ORCs) for internal combustion engine waste heat recovery (ICE-WHR). Renew. Sustain. Energy Rev. 2018, 92, 95-110. [CrossRef]

15. Garciaa, S.I.; Garcia, R.F.; Carril, J.C.; Garcia, D.I. A review of thermodynamic cycles used in low temperature recovery systems over the last two years. Renew. Sustain. Energy Rev. 2018, 81, 760-767. [CrossRef]

16. Kim, K.H.; Han, C.H.; Kim, K. Effects of ammonia concentration on the thermodynamic performances of ammonia-water based power cycles. Thermochimca Acta 2012, 530, 7-16. [CrossRef]

17. Kim, K.H.; Ko, H.J.; Kim, K. Assessment of pinch point characteristics in heat exchangers and condensers of ammonia-water based power cycles. Appl. Energy 2014, 113, 970-981. [CrossRef]

18. Lai, N.A.; Fischer, J. Efficiencies of power flash cycles. Energy 2012, 44, 1017-1027. [CrossRef] 
19. Ho, T.; Mao, S.S.; Greif, R. Comparison of the Organic Flash Cycle (OFC) to other advanced vapor cycles for intermediate and high temperature waste heat reclamation and solar thermal energy. Energy 2012, 42, 213-223. [CrossRef]

20. Ho, T.; Mao, S.S.; Greif, R. Increased power production through enhancements to the Organic Flash Cycle (OFC). Energy 2012, 45, 686-695. [CrossRef]

21. Bombarda, P.; Gaia, M.; Invernizzi, C.; Pietra, C. Comparison of Enhanced Organic Rankine Cycles for Geothermal Power Units. In Proceedings of the World Geothermal Congress, Melbourne, Australia, 19-25 April 2015.

22. Lee, H.Y.; Park, S.H.; Kim, K.H. Comparative analysis of thermodynamic performance and optimization of Organic Flash Cycle (OFC) and Organic Rankine Cycle (ORC). Appl. Therm. Eng. 2016, 100, 680-690. [CrossRef]

23. Mondal, S.; De, S. Power by waste heat recovery from low temperature industrial flue gas by Organic Flash Cycle (OFC) and transcritical- $\mathrm{CO}_{2}$ power cycle: A comparative study through combined thermodynamic and economic analysis. Energy 2017, 121, 832-840. [CrossRef]

24. Mondal, S.; De, S. Ejector based organic flash combined power and refrigeration cycle (EBOFCP\&RC)—A scheme for low grade waste heat recovery. Energy 2017, 134, 638-648.

25. Mondal, S.; Alam, S.; De, S. Performance assessment of a low grade waste heat driven Organic Flash Cycle (OFC) with ejector. Energy 2018, 163, 849-862. [CrossRef]

26. Li, Z.; Lu, Y.; Huang, Y.; Qian, G.; Chen, F.; Yu, X.; Roskilly, V. Comparison study of Trilateral Rankine Cycle, Organic Flash Cycle and basic Organic Rankine Cycle for low grade heat recovery. Energy Procedia 2017, 142, 1441-1447. [CrossRef]

27. Nemati, A.; Nami, H.; Yari, M. Assessment of different configurations of solar energy driven organic flash cycles (OFCs) via exergy and exergoeconomic methodologies. Renew. Energy 2018, 115, 1231-1248. [CrossRef]

28. Baccioli, A.; Antonelli, M. Organic Flash Cycles: Off-design behavior and control strategies of two different cycle architectures for Waste Heat Recovery applications. Energy Convers. Mgmt. 2018, 157, 176-185. [CrossRef]

29. Baccioli, A.; Antonelli, M.; Desideri, U. Technical and economic analysis of organic flash regenerative cycles (OFRCs) for low temperature waste heat recovery. Appl. Energy 2017, 199, 69-87. [CrossRef]

30. Mosaffa, A.H.; Zareei, A. Proposal and thermoeconomic analysis of geothermal flash binary power plants utilizing different types of organic flash cycle. Geothermics 2018, 72, 47-63. [CrossRef]

31. Kim, K.H.; Han, C.H.; Ko, H.J. Comparative Thermodynamic Analysis of Kalina and Kalina Flash Cycles for Utilizing Low-Grade Heat Source. Energies 2018, 11, 3311. [CrossRef]

32. Yang, T.; Chen, G.J.; Guo, T.M. Extension of the Wong-Sandler mixing rule to the three-parameter Patel-Teja equation of state: Application up to the near-critical region. Chem. Eng. J. 1997, 67, 27-36. [CrossRef]

33. Gao, J.; Li, L.D.; Zhu, Z.Y.; Ru, S.G. Vapor-liquid equilibria calculation for asymmetric systems using Patel-Teja equation of state with a new mixing rule. Fluid Phase Equilibria 2004, 224, 213-219. [CrossRef]

34. Yaws, C.L. Chemical Properties Handbook; McGraw-Hill: New York, NY, USA, 1999.

35. Delgado-Torres, A.M.; García-Rodríguez, L. Preliminary assessment of solar organic Rankine cycles for driving a desalination system. Desalination 2007, 216, 252-275. [CrossRef]

(C) 2019 by the author. Licensee MDPI, Basel, Switzerland. This article is an open access article distributed under the terms and conditions of the Creative Commons Attribution (CC BY) license (http://creativecommons.org/licenses/by/4.0/). 